\title{
DEL BESO DE LA MUJER ARAÑ A AL DE LA TÍA JULIA: ESTRUCTURA Y DINÁMICA INTERIOR
}

\author{
Por \\ DANIEL R. REEDY \\ University of Kentucky
}

En su famosa "Rima XXIX" Gustavo Adolfo Bécquer describe en términos inolvidables los efectos de un beso en su evocación de los amores ilicitos de Paolo Malatesta y Francesca da Rimini en el Infierno de Dante:

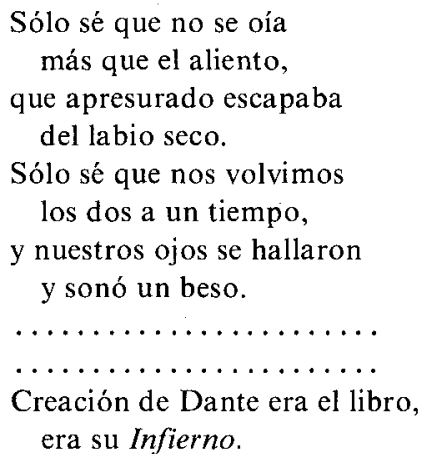

(G.A. Bécquer, "Rima XXIX”, versos 11-22)

Los puntos suspensivos que siguen al beso son un excelente ejemplo del lenguaje de silencio que brinda a la imaginación una relación más íntima como la de Paolo y Francesca. Esto, a su vez, nos hace pensar no sólo en el beso como expresión física de afecto y amor, sino también como manifestación universal de dos almas, no conformes con las normas sociales de su tiempo, en busca de una perfecta unión.

Se pueden encontrar algunas semejanzas entre el caso de la pareja de Dante, evocada por Bécquer, y la unión descrita por Manuel Puig en El beso de la mujer araña (1976) y por Mario Vargas Llosa en La tía Julia y el escribidor (1977). En cada uno de los tres textos, el amor triunfa a pesar de las restricciones de una sociedad que suele condenar tales relaciones: el adulterio de Paolo y Francesca, la unión entre un homosexual y un revolucionario en Puig, y las frenéticas relaciones entre un joven peruano y su propia tía en la 
obra de Vargas Llosa. Los paralelos que pueden trazarse entre la novela de Puig y la de Vargas Llosa provienen tanto de las semejanzas del contenido temático como de los conceptos de estructura narrativa.

No nos proponemos demostrar que influyó una novela en la otra, sino señalar sus semejanzas más importantes. Se parecen, por ejemplo, en el empleo de trozos de película en una novela y en la otra de segmentos de radioteatro dentro de otra historia de personajes cuya vida personal y relaciones íntimas los sitúa al margen de la sociedad. En la novela de Puig vemos la problemática de un homosexual que es compañero de celda de un revolucionario de izquierda, y en La tía Julia y el escribidor, la historia de un joven enamorado, deseoso de casarse con su tía, una divorciada. A pesar de que ambas novelas parecen sentimentales, de marcada sencillez, y de tono cursi, nos parece que hay otros niveles de significado que contribuyen al valor de estas obras.

\section{El beso de la mujer araña}

El beso de la mujer araña está organizada alrededor de aspectos de la vida diaria de dos compañeros de celda-Molina, sentenciado a ocho años de prisión por delito de corrupción de menores, y Valentín, activista y revolucionario. A través de los diálogos entre los prisioneros, unos monólogos interiores, e informes penales, nos enteramos de ciertos detalles de la vida de cada uno antes de ingresar en la penitenciaría, y se nos revela su interioridad más íntima. Sabemos, por ejemplo, que la principal inquietud de Molina proviene de su vida como homosexual y de los problemas que ha tenido que confrontar en el pasado-en especial la falta de amistades o relaciones que fueran permanentes, y el sufrimiento de su madre causado por su estilo de vida. En contraste, Valentín es un hombre dedicado a causas revolucionarias que convierten su ideología en dogma. Al comienzo los dos protagonistas representan polos opuestos en su filosofía de vida y en la percepción de su propia sexualidad-Valentín es firmemente heterosexual y Molina se concibe a sí mismo como hembra--, pero poco a poco la polaridad va desapareciendo hasta que por fin las relaciones entre los dos llegan a estrecharse. Este proceso se lleva a cabo a través de Molina que se entretiene a sí mismo y a su compañero de celda, contándole varias películas que ha visto. Según nos dice el mismo Puig en una entrevista, algunas de las seis películas relatadas en la novela son verdaderas, aunque otras son invenciones suyas o versiones de filmes vistos años antes de escribir su obra. ${ }^{1}$ Contadas en largos trozos por Molina con sus propias impresiones y embellecimientos, las

\footnotetext{
${ }^{1}$ Marcelo Coddou, "Seis preguntas para Manuel Puig sobre su última novela: El beso de la mujer araña", The American Hispanist, 2, No. 15 (May 1977), 12-13.
} 
películas forman un puente sobre el golfo que separa a los protagonistas y funcionan como vía de acercamiento entre los dos. La técnica empleada por Puig hace pensar en el papel de Scherezade en Las mil y una noches, aunque el propósito es otro.

Todas las películas están relacionadas con la situación de Molina y Valentín por la temática del contenido; es decir que cada película versa sobre una historia amorosa en la cual hay personas cuya vida y felicidad son a menazadas por fuerzas ajenas a su control. En la primera película, una mujer pantera está amenazada por la maldición de sus antepasados; en otra, una cantante francesa traiciona a los suyos por un oficial nazi; en la cuarta, un joven abandona para siempre a sus familiares para convertirse en revolucionario. Según los comentarios de la profesora Masiello, cada historia narrada en las películas se perfila según un molde de amor, conflicto, separación y resolución. ${ }^{2} \mathrm{Y}$ sabemos que los personajes son individuos incapaces de adaptarse a las normas sociales de su ambiente.

El lento proceso de acercamiento íntimo entre Molina y Valentín se entiende mejor en relación al contenido de las películas y los actos de ternura de Molina para con Valentín. Las películas, entonces, son el lugar de contacto, o sea el territorio común entre los dos hombres, y sirven de ligazón entre ellos. La reacción de Valentín de incrédulo ante detalles de la vida íntima de Molina no es sorprendente porque él es incapaz de comprender que un hombre pueda considerarse psicológicamente una mujer y referirse a sí mismo en términos femeninos. Pero al enfermarse Valentín, éste deja que Molina lo cuide, aceptando su comida, dejando que lo limpie como una madre a su hijo cuando se ensucia.

No son sólo las películas las que se relacionan al asunto de la novela. Por ejemplo, como anticipo de lo que va a ocurrir luego, el lector notará los versos de un bolero, "Mi carta", cantado por Molina sobre "los sueños tristes de este amor extraño". ${ }^{3}$ Cuando ocurren las inevitables relaciones sexuales entre los hombres por primera vez, éstas no son el resultado de una seducción llevada a cabo exclusivamente por Molina, sin consecuencia del deseo de Valentín de mostrar su agradecimiento personal por el fiel trato recibido de Molina. El mutismo de Valentín producido por el enlace es correspondido por el aparente gozo de Molina que se siente convertido en otro y transportado a otra esfera (p. 224). Más tarde, Molina explica que se siente contentísimo, declarando a su compañero, "Valentín... yo creo que desde que era chico que no me siento

\footnotetext{
${ }^{2}$ Francine R. Masiello, "Jail House Flicks: Projections by Manuel Puig", Symposium, 32, No. 1 (Spring 1978), 18.

${ }^{3}$ Manuel Puig, El beso de la mujer araña (Barcelona: Seix Barral, 1976), p. 137. Páginas de citas subsiguientes son de esta edición y se darán entre paréntesis dentro del cuerpo del estudio.
} 
tan contento. Desde que mamá me compraba algún juguete, o algo así". (p. 224).

La última película narrada por Molina - la de la historia de una desdichada cantante mexicana y su novio-sirve como presagio de lo que ocurrirá luego entre Molina y Valentín. La joven de la película se ve obligada a convertirse en buscona para mantener a su novio que está muy enfermo-acción que hace pensar en el sacrificio de Nacha Regules en la novela de Manuel Gálvez. Cuando al fin el novio muere, dejando solo a la pobre señorita, Molina le explica a Valentín que el final no es enigmático como cree éste, sino lo mejor de la película:

-Quiere decir que aunque ella se haya quedado sin nada, está contenta de haber tenido por lo menos una relación verdadera en la vida, aunque ya se haya terminado. (p. 263)

El descubrimiento de los desdichados amantes de "una relación verdadera en la vida" es la clave de la meta perseguida por Molina. No nos asombre entonces que el primer beso entre los dos ocurre después de la narración de esta película, y sirve para reforzar entre los dos el vínculo que sobrepasa lo puramente físico-sexual. Ambos han encontrado "una relación verdadera"en la vida, y el beso es el reconocimiento simbólico del amor y de un casamiento ritual.

Al concluirse la acción de la novela - lo cual se produce rápidamentedejan libre a Molina pero éste es asesinado por extremistas, y a Valentín lo torturan en la prisión hasta llevarlo al borde de la muerte. Las últimas escenas, que son como una película en blanco y negro, giran alrededor de las atormentadas divagaciones de Valentín que sueña con la "mujer araña", o sea Molina, que habita "una isla feliz". Allí en la "isla feliz" de la muerte parecen reunirse Valentín y Molina por última vez.

\section{La tía Julia y el escribidor}

En vez de emplear películas en su novela, la cual es sumamente autobiográfica, ${ }^{4}$ Vargas Llosa hace uso de una serie de segmentos de radioteatro-los cuales son creaciones del famoso escribidor, Pedro Camacho, que los compone al correr de la pluma para el creciente público de aficionados que tiene en Lima. Como ya dijimos, la historia de Mario Varguitas y su tía Julia está presentada al lado de episodios melodramáticos cuyos elementos absurdos sobrepasan el caso de un joven de dieciocho años que quiere casarse con su tía, una divorciada de más de treinta. Da relieve a la historia el contrapunto de los ridículos episodios escritos por Pedro Camacho acerca de

\footnotetext{
${ }^{4}$ Sobre los aspectos autobiográficos de la novela, véase la entrevista de Ma rio Vargas Llosa dada a José Miguel Oviedo, "Conversación con Mario Vargas Llosa sobre La tía Julia y elescribidor", Texas Studies in Literature and Language, 9, No. 4 (Winter 1977), 546-559.
} 
incesto, asesinatos por la policía, violación de menores, parricidio, y cataclismos naturales que crecen en intensidad e incredibilidad mientras avanza el deterioro psicológico del escribid or.

Consta señalar que las relaciones entre Varguitas y su tía Julia corren paralelamente, aunque en plano menor, con el enlace entre Molina y Valentín. En a mbos casos, la conducta de los personajes centrales abre una brecha en la muralla de los tabúes sociales. En La tía Julia y el escribidor, Varguitas, como el héroe prototipo de los mitos, tiene que vencer los estorbos creados por amigos, familiares, y las leyes que dificultan su obsesivo deseo de casarse con su tía-obsesión que lo motiva desde la ocasión del primer beso. Aunque la naturaleza de la situación de Varguitas parezca frívola, puede considerarse desde otro punto de vista que el joven protagonista se encuentra en una etapa decisiva de transición y transformación sicológica. Raymond Williams, por ejemplo, ha examinado el tema de escribidor/escritor que se manifiesta no sólo en el papel de Pedro Camacho (el escribidor) sino también en Varguitas, joven artista cuyos cuentos dan testimonio de que no ha pasado todavía de escribidor a escritor. ${ }^{5}$ Además, está entre mocoso y adulto, entre soltero y casado, entre novio frívolo y amante serio; podría considerársele como partícipe en un rito, en el cual lo fuerzan a desafiar las normas de una sociedad que condena su conducta.

Comparadas con el caso de Mario Varguitas, las historias desarrolladas en el radioteatro de Pedro Camacho se extienden más allá de los límites de 1o posible. Claro está que todo aficionado al radioteatro o a la telenovela contemporánea está acostumbrado a encontrar las más exageradas circunstancias. Entre los escritos del escribidor el segmento sobre el Dr. Quintero, por ejemplo, versa sobre el tema del incesto entre hermanos; en otro, es la historia de la supuesta violación de una menor de edad por Gumersindo Tello, Testigo de Jehová; o el caso del gerente de la Compañía de Antirroedores ultimado por sus hijas y su mujer. Quizá la más inaudita es la historia del Padre Seferino Huanca Leyva quien propone a sus feligreses el beneficio del onanismo, la venta de estampitas de desnudas, el entrenamiento de prostitutas, y la creación de una escuela de ladrones. Comparado con el comportamiento antisocial de estos personajes ficticios, el caso de Mario Varguitas no puede tomarse muy en serio.

Las relaciones entre Varguitas y su tía Julia tienen sus altibajos, correspondiendo quizá a un ritmo establecido por los programas de radioteatro. No es amor a primera vista, porque al conocerla por primera vez, Varguitas reacciona con rabia cuando su tía le besa en la mejilla como a un niño:

\footnotetext{
${ }^{5}$ Raymond L. Williams, "La tía Julia y el escribidor: escritores y lectores", Texto Crítico, 13, (1979), 197-209.
} 
La odié a muerte. Mis leves choques con la familia en ese entonces, se debían a que todos se empeñaban en tratarme todavía como un niño y no como lo que era, un hombre completo de dieciocho años. Nada me irritaba tanto como el Marito; tenía la sensación de que el diminutivo me regresaba al pantalón corto. ${ }^{6}$

Estas líneas también sirven para dar énfasis a nuestra aseveración de que las circunstancias de Varguitas se asemejan a una especie de rito de iniciación, o sea un período de transición y diferenciación psíquica.

El cambio de actitud de Varguitas hacia su tía tiene un pronto desarrollo, y el desprecio y odio iniciales se convierten en una actitud de joven amante. El cambio se ve claramente durante un baile al que asisten en el Grill del Hotel Bolívar, porque es el momento cuando la besa en los labios por primera vez:

Ella separó un poco la cara para mirarme e intentó sonreír, y entonces, en una acción casi mecánica, me incliné y la besé en los labios. Fue un contacto muy rá pido pero no lo esperaba y la sorpresa hizo que esta vez dejara un momento de bailar. Ahora su estupefacción era total: abría los ojos y estaba con la boca abierta. (p. 75)

Desde aquel momento, semejante a lo ocurrido en Puig, la naturaleza clandestina de las relaciones entre los dos se complica, debido a la preocupación de la tía Julia porque le lleva 14 años a Varguitas, y por la antipatía de la familia de Varguitas para quienes es casi un incesto entre madre e hijo-tema anunciado en el texto a través de una película mexicana titulada "Madre y amante". Por fin, tras centenares de obstáculos, algunos tan melodramáticos y absurdos que rivalizan los del radioteatro de Camacho, Varguitas logra convencer a su tía a que se case con él, aunque siguen los problemas de la escasez de dinero, la falta de autorización notarial de sus padres, siendo él menor de edad, y la romería de visitas a distintos oficiales a lo largo del litoral peruano, tratand o de encontrar a alguien que los case en boda civil.

Casados por fin, Varguitas tiene que enfrentar otros problemas más serios-los llantos inconsolables de su madre, la rabia y violencia de su padre que jura matarlo y hacerle botar a la tía Julia del país, la separación de la pareja cuando la tía Julia viaja a Chile, y la acumulación de siete trabajos para mantener a su esposa cuand o ella vuelve a Lima. Pero todo queda resuelto y al contrario de las historias de Pedro Camacho que siempre parecen concluir en tragedia, se descubre en el último capítulo de la novela que la felicidad entre la tía Julia y Varguitas reinó ocho años, terminando en divorcio, aunque según Varguitas "el matrimonio. . fue realmente un éxito...."(p. 429) Durante los años de casados, los sueños de Varguitas se volvieron realidad: vivió en una

\footnotetext{
${ }^{6}$ Mario Vargas Llosa, La tía Julia y el escribidor (Barcelona: Seix Barral, 1977), p. 16. Páginas de
} citas subsiguientes son de esta edición y se darán entre paréntesis dentro del cuerpo del estudio. 
famosa buhardilla de París, se hizo escritor con la publicación de unos libros, y se volvió a casar, esta vez con su prima. El cambio más notable en Varguitas es su actitud pacífica, resultado, quizá, de haber vencido los obstáculos anteriores. Se casó con la mujer que amaba; dejó atrás su apariencia de mocoso para convertirse en hombre responsable; y se completó la transformación de escribidor en escritor.

En resumen, señalamos que en ambas novelas, hay un entrelazarse de técnicas narrativas tradicionales con lo no tradicional. En El beso de la mujer araña encontramos el empleo de segmentos de películas con el texto dialogado entre Valentín y Molina, y en La tía Julia y el escribidor, los distintos segmentos de radioteatro forman un texto pareja con la historia autobiográfica de Varguitas. La inclusión de materias ficticias de películas y radioteatro-provenientes de otros medios artísticos-nos da un curioso contrapunto de ficción con realidad/ ficción donde los dos mundos co-existen. Para ambos grupos de personajes, Molina/Valentín y Varguitas/tía Julia, sus relaciones heterodoxas producen un resultado de suma importancia para cada uno de los partícipes. Para Molina y Valentín nace un cariño y un amor que supera su naturaleza innata de homosexual y revolucionario. La unión entre ellos y entre Varguitas y la tía Julia es una especie de manifestación secular de casa miento sacro, producto de un rito del cual pueda evolucionar la felicidad de cada uno. Molina descubre en Valentín un verdadero cariño y éste encuentra en Molina un sentido de compasión y sensibilidad no encontrado jamás en sus actividades revolucionarias. En el caso de Varguitas y la tía Julia, el lector sigue sus aventuras algo escéptico hasta el final de la obra, esperando el momento en que se le presente algún estorbo insuperable; pero, ocurre lo contrario. Para Varguitas, el casarse parece corresponder a un proceso de auto-aserción, de liberación, y de madurez, marcando su transición de adolescente a hombre. Y a la tía Julia le tocó más tiempo que los cinco años de felicidad que pidió a Varguitas cuando decidió casarse con él.

Hemos de hacer notar que estas obras de Puig y Vargas Llosa no han sido universalmente bien recibidas por la crítica. En una reseña de El beso de la mujer araña, el novelista Robert Coover describe la obra como "a rather frail little love story that Mr. Puig's fans will perhaps find thin and disappointing"? Y Antonio Cornejo Polar, escribiendo en la Revista de Crítica Literaria Hispanoamericana sobre La tia Julia..., dice que "significa una ampliación

\footnotetext{
${ }^{7}$ Robert Coover, "Old, New, Borrowed, Blue: Review of Kiss of the Spider Woman by Manuel Puig", New York Times Book Review 22 April 1979, p. 15.
} 
del horizonte creador de Vargas Llosa, sin duda, pero una a mpliación que no enriquece el desarrollo de su obra". ${ }^{8}$ Comparadas con algunas de las novelas magistrales del auge de la Nueva Novela, éstas son más sencillas y sentimentales aunque no desprovistas de valor literario, como creemos haber demostrado. Es posible, también, por bien o por mal, que estas novelas y otras como La cabeza de la hidra de Fuentes y La misteriosa desaparición de la marquesita de Loria de Donoso estén marcando un nuevo hito en el desarrollo de la novela en Hispanoamérica.

\footnotetext{
${ }^{8}$ Antonio Cornejo Polar, "Reseña de Vargas Llosa, La tia Julia y el escribidor", Revista de Crítica Literaria Latinoamericana, 6 (1977), 161.
} 